\section{FRI0135 PREDICTORS FOR SHORT-TERM CLINICAL EFFECTIVENESS OF BARICITINIB IN RHEUMATOID ARTHRITIS PATIENTS IN ROUTINE CLINICAL PRACTICE: DATA FROM A JAPANESE MULTICENTER REGISTRY}

N. Takahashi' ${ }^{1}$, T. Kojima ${ }^{1}$, S. Asai ${ }^{1}$, K. Terabe ${ }^{1}$, N. Ishiguro ${ }^{1}$ on behalf of TBCR Study Group. ${ }^{1}$ Nagoya University Graduate School of Medicine, Nagoya, Japan

Background: Baricitinib is considered as a specific JAK $1 / 2$ inhibitor. While a number of randomized controlled trials have reported on the clinical efficacy and safety profile of baricitinib in rheumatoid arthritis (RA) patients, clinical data for RA patients in routine clinical practice are scarce.

Objectives: This study aimed to evaluate the short-term effectiveness and safety profiles of baricitinib and explore factors associated with improved short-term effectiveness in patients with RA in clinical settings.

Methods: A total of 113 consecutive RA patients who had been treated with baricitinib were registered in the TBCR, a Japanese multicenter registry for RA patients treated with biologics or JAK inhibitors (targeted DMARDs) [3], and followed for at least 24 weeks. Univariate and multivariate logistic regression analysis was used to study predictive factors for achievement of low disease activity (LDA) at 24 weeks. Results: Mean age was 66.1 years, mean RA disease duration was 14.0 years, $71.1 \%$ had a history of use targeted DMARDs, and $48.3 \%$ and $40.0 \%$ were receiving concomitant methotrexate (MTX) and oral prednisone, respectively. Mean DAS28-CRP significantly decreased from 3.55 at baseline to 2.32 at 24 weeks (Figure 1A). At 24 weeks, $68.2 \%$ and $64.1 \%$ of patients achieved LDA and moderate or good response, respectively (Figure 1B). Multivariate logistic regression analysis revealed that no previous targeted DMARD use and lower DAS28-CRP score at baseline were independently associated with achievement of LDA at 24 weeks (Table). While the percent change in DAS28-CRP was similar regardless of whether patients used concomitant MTX (Figure 2A), patietns with previous use of targeted DMARDs (Switch group) showed lower percent improvement in DAS28-CRP compared to targeted DMARDs-naïve patients (Naïve group) (Figure 2B). The overall retention rate for baricitinib was $86.5 \%$ at 24 weeks, as estimated by Kaplan-Meier analysis. The discontinuation rate due to adverse events was $6.5 \%$ at 24 weeks. In the present study cohort, seven patients developed herpes zoster, with an incidence rate of 8.4 per 100 patientyears. All seven patients were treated with antiviral agents for herpes zoster and restarted baricitinib treatment.

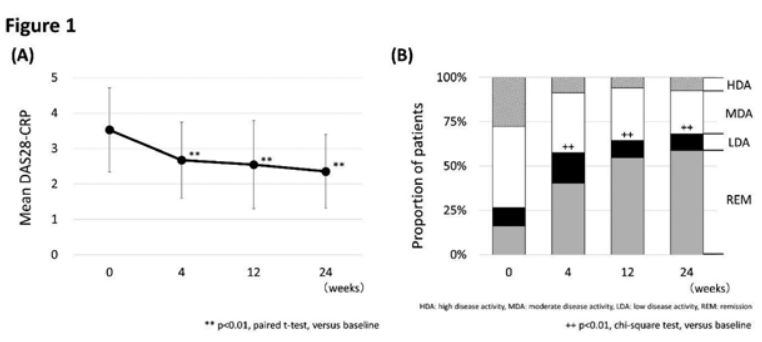

Table

\begin{tabular}{|c|c|c|c|c|}
\hline \multirow[b]{2}{*}{ variables } & \multicolumn{2}{|l|}{ Univariate } & \multicolumn{2}{|l|}{ Multivariate } \\
\hline & OR $(95 \% \mathrm{Cl})$ & $\mathrm{p}$-value & adjusted OR $(95 \% \mathrm{Cl})$ & $\mathrm{p}$-value \\
\hline Male & $1.17(0.43-3.16)$ & 0.755 & & \\
\hline Age, $<65$ years & $1.46(0.62-3.44)$ & 0.388 & & \\
\hline Disease duration, $<10$ years & $1.41(0.61-3.23)$ & 0.419 & & \\
\hline ACPA positive & $1.56(0.51-4.80)$ & 0.433 & & \\
\hline no previous biological DMARDs & $4.67(1.49-14.66)$ & 0.008 & $33.4(2.53-442.62)$ & 0.008 \\
\hline concomitant MTX & $0.860(0.40-2.02)$ & 0.789 & & \\
\hline concomitant PSL & $0.24(0.10-0.56)$ & 0.001 & & \\
\hline DAS28-CRP@baseline & $0.55(0.38-0.80)$ & 0.002 & $0.28(0.13-0.62)$ & 0.002 \\
\hline mHAQ@baseline & $0.27(0.09-0.77)$ & $\begin{array}{l}0.015 \\
\text { Bold ita }\end{array}$ & alic, $p<0.05$ & \\
\hline
\end{tabular}

\section{Conclusion:}

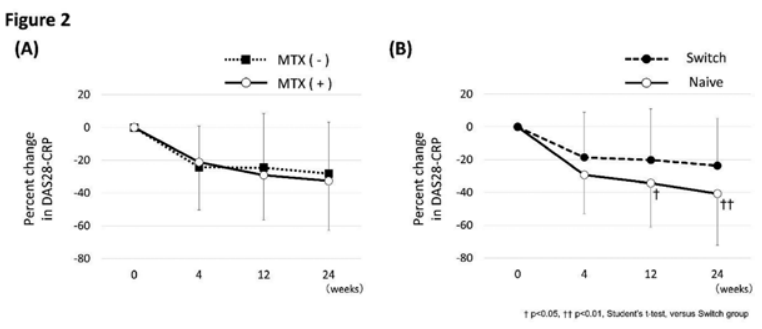

In this study, we demonstrated the short-term clinical effectiveness and safety profile of baricitinib in Japanese RA patients in the 'real-world' setting. To the best of our knowledge, this study is the first to report the clinical outcomes of baricitinib in routine clinical practice in Japan. Baricitinib significantly improved disease activity, with an expected safety profile. We observed some interesting features regarding the effectiveness of baricitinib. Baricitinib was significantly more effective when used as a first-line targeted DMARD and may play a key role in the modern treatment strategy for RA, although careful observation is necessary for possible complications and AEs including herpes zoster.

References:

[1] Taylor PC, et al. (2017) The New England journal of medicine. 376(7), 652.

[2] Tanaka Y, et al. (2018) Modern rheumatology. 28(1), 20-9.

[3] Takahashi N, et al. (2014) Rheumatology (Oxford) 2014

Disclosure of Interests: Nobunori Takahashi Speakers bureau: AbbVie, Asahi Kasei, Astellas, Bristol-Myers Squibb, Chugai, Daiichi-Sankyo, Eisai, El Lilly, Janssen, Mitsubishi Tanabe, Ono, Pfizer, Takeda, and UCB Japan, Toshihisa Kojima Grant/research support from: Chugai, Eli Lilly, Astellas, Abbvie, and Novartis, Consultant of: AbbVie, Speakers bureau: AbbVie, Astellas, Bristol-Myers Squibb, Chugai, Daiichi-Sankyo, Eli Lilly, Janssen, Mitsubishi Tanabe, Pfizer, and Takeda, Shuji Asai Speakers bureau: AbbVie, Astellas, Bristol-Myers Squibb, Chugai, Daiichi-Sankyo, Eisai, Janssen, Takeda, and UCB Japan, Kenya Terabe: None declared, Naoki Ishiguro Grant/research support from: AbbVie, Asahi Kasei, Astellas, Chugai, Daiichi-Sankyo, Eisai, Kaken, Mitsubish Tanabe, Otsuka, Pfizer, Takeda, and Zimmer Biomet, Consultant of: Ono, Speakers bureau: Astellas, Bristol-Myers Squibb, Daiichi-Sankyo, Eli Lilly, Pfizer, and Taisho Toyama

DOI: 10.1136/annrheumdis-2020-eular.2697

\begin{tabular}{|l|l}
\hline FRI0136 & PERIPHERAL PROTEIN BIOMARKER CHANGES \\
FOLLOWING SELECTIVE INHIBITION OF JANUS \\
KINASE 1 (JAK1) BY FILGOTINIB IN ADULTS WITH \\
MODERATELY-TO-SEVERELY ACTIVE RHEUMATOID \\
ARTHRITIS WITH PRIOR INADEQUATE RESPONSE TO \\
METHOTREXATE (FINCH1)
\end{tabular}

P. C. Taylor ${ }^{1}$, E. Elboudwarej ${ }^{2}$, B. Downie ${ }^{2}$, J. Liu², R. E. Hawtin², A. M. Mirza ${ }^{2} .{ }^{1}$ University of Oxford, Botnar Research Centre, Nuffield Department of Orthopaedics, Rheumatology and Musculoskeletal Sciences, Oxford, United Kingdom; ${ }^{2}$ Gilead Sciences Inc., Foster City, United States of America

Background: Filgotinib (FIL), an oral selective Janus kinase 1 (JAK1) inhibitor has shown efficacy and safety in multiple phase 3 studies in adults with moderately-to-severely active rheumatoid arthritis (RA), including those with prior inadequate response to methotrexate (MTX) therapy (FINCH1; NCT02889796).

Objectives: A longitudinal study of protein biomarkers related to JAK signaling $^{1}$, bone biology ${ }^{2}$, immune cell migration ${ }^{2}$, and inflammation ${ }^{2}$ was conducted to identify RA-associated markers altered by FIL vs MTX or adalimumab (ADA).

Methods: FINCH1 RA patients (pts) were randomized to receive either a stable dose of MTX with placebo (PBO+MTX), ADA+MTX, and either FIL100mg+MTX or FIL200mg+MTX, once daily. Plasma, serum, and urine samples were taken from a subset of pts ( 548) at baseline (BL) and weeks (wks) 4 and 12 Twenty-six pre-defined cytokines (biomarkers) were evaluated using ELISA $\mathrm{BL}$ correlation between biomarkers and clinical response measures (DAS28CRP, SJC28, TJC28, CDAI, Patient Assessment and FACIT), were analyzed by Spearman Rank. Multiscale bootstrap resampling evaluated significant intra-cluster biomarker membership. Mean changes in biomarker levels from $\mathrm{BL}$ to wks 4 and 12 were compared between arms using PBO-adjusted estimates from a linear mixed effects model. A $5 \%$ false-discovery rate was applied for all analyses.

Results: At BL, distinct biomarker-based pt clusters $(\mathrm{CL})$ were identified. The strongest intra-group correlations were in bone-cartilage resorption/inflammation (CL1; Rho range $0.37-0.88$ ) and JAK activity (CL2; Rho range $0.41-0.71$ ) Individual BL cytokine levels were significantly associated with DAS28CRP, with unique biomarkers specific to various subcomponents of the score. Eleven biomarkers were associated with DAS28CRP, while 5, 3, and 2 were associated with CDAI, SJC28, and TJC28, respectively. The magnitude of FIL-associated treatment effects was time- and dose-dependent. Significant biomarker changes from $\mathrm{BL}$ were observed in FIL pts, relative to PBO+MTX pts. FIL100mg+MTX led to a significant change in 8 biomarkers by either 4 or 12 wks of treatment; FIL200mg+MTX significantly changed these and an additional 4 biomarkers by either time point. The greatest effect of FIL200mg+MTX was at 12 wks for CXCL13 (-38.4\%) and IL6 (-53.7\%). All treatment arms led to significant reductions in TNFa relative to PBO+MTX. FIL200mg+MTX treatment led to larger reductions of TNFa than ADA+MTX treatment at both wk4 (-24.7\% vs $-17.9 \%)$ 
and wk12 (-20.5\% vs $-12.2 \%)$, although the differences were not statistically significant.

FIL and ADA caused differential patterns of cytokine response at either wks 4 or 12. Of 12 biomarkers with a significant FIL200mg+MTX treatment effect, there was a significantly larger reduction in TNFSF13B and CTX1 relative to ADA+MTX at 12 wks. Of 8 biomarkers with FIL100mg+MTX effects, only 2 (CXCL10 at wk 4; CXCL13 at wks 4 and 12) had significant differences from ADA+MTX. Relative either to FIL200mg+MTX or FIL100mg+MTX, and despite the same direction of effect, ADA+MTX led to a significantly larger reduction in CCL2, CXCL10, CCL4, and $\mathrm{CXCL} 13$.

Conclusion: Compared with PBO, 12 wks of FIL treatment significantly reduced cytokines associated with JAK activity ${ }^{1}$, bone biology ${ }^{2}$, inflammation ${ }^{2}$, and immune cell migration ${ }^{2}$ in MTX-IR pts. The effects were largely FIL dose-dependent; most cytokines exhibited similar effects regardless of treatment arms, but differential changes between FIL+MTX and ADA+MTX were observed, supportive of the different mechanisms of action of these therapies.

References:

[1] Majoros A, et al. Front Immunol. 2017;8:29

[2] Brennan F, and McInnes I. J Clin Invest. 2008;118:3537-45

Acknowledgments: This study was funded by Gilead Sciences, Inc. Editorial support was provided by Fishawack Communications Inc and funded by Gilead Sciences, Inc.

Disclosure of Interests: Peter C. Taylor Grant/research support from: Celgene, Eli Lilly and Company, Galapagos, and Gilead, Consultant of: AbbVie, Biogen, Eli Lilly and Company, Fresenius, Galapagos, Gilead, GlaxoSmithKline, Janssen, Nordic Pharma, Pfizer Roche, and UCB, Emon Elboudwarej Shareholder of: Gilead Sciences Inc., Employee of: Gilead Sciences Inc., Bryan Downie Shareholder of: Gilead Sciences Inc., Employee of: Gilead Sciences Inc., Jinfeng Liu Shareholder of: Gilead Sciences Inc., Roche, Employee of: Gilead Sciences Inc., Rachael E. Hawtin Shareholder of: Gilead Sciences Inc., Employee of: Gilead Sciences Inc., Amer M. Mirza Shareholder of: Gilead Sciences Inc., Employee of: Gilead Sciences Inc.

DOI: 10.1136/annrheumdis-2020-eular.4704

\section{FRI0137 DISCONTINUATION OF BARICITINIB AFTER ACHIEVING LOW DISEASE ACTIVITY IN PATIENTS WITH RHEUMATOID ARTHRITIS IN CLINICAL PRACTICE; A MULTICENTER OBSERVATIONAL STUDY.}

E. Torikai ${ }^{1}$, Y. Hirano ${ }^{2}$, D. Suzuki ${ }^{3}$, Y. Kanayama ${ }^{4} .{ }^{1}$ I wata city hospital, Iwata, Japan; ${ }^{2}$ Toyohashi Municipal Hospital, Toyohashi, Japan; ${ }^{3}$ Futaba clinic, Iwata, Japan; ${ }^{4}$ Toyota Kosei Hopital, Toyota, Japan

Background: Baricitinib (bari) is an oral Janus kinase (JAK) 1/JAK2 selective inhibitor that has shown good efficacy in patients with RA and adequate response to conventional synthetic DMARDs in some clinical trials [1,2]. However, concerning the high cost and long-term safety related to the inhibition of particular molecules, we would like to discontinue bari after achieving long low disease activity (LDA).

Objectives: To evaluate the clinical outcomes in patients with RA who discontinued bari after achieving LDA for 24 weeks in real-world multicenter clinical data.

Methods: Japanese 67 patients with RA who show an inadequate response to csDMARDs or bDMARDs were scheduled to receive bari 4 or $2 \mathrm{mg} / \mathrm{day}$ once daily dose as a monotherapy or in combination with other csDMARDs. We included 51 patients who achieved and maintained LDA at least for 24 weeks after baricitinib therapy. They were allowed to decrease baricitinib after discontinuation of prednisolone. Bari was either discontinued or continued after study enrolment. The decision of discontinuation and continuation of baricitinib was determined based on patient-physician decision making with informed consent. We divided patients into two groups: a discontinuation group ( $D$ group; $n=23$ ) and a continuation group ( $C$ group; $n=28$ ). We evaluated the proportion of patients who remained LDA for 24 weeks in both groups. Clinical outcomes including Clinical Disease Activity Index (CDAI), and HAQ-DI were compared between both groups. The last observational carried forward method was used for patients who could not discontinue baricitinib due to flare before 24 weeks. In D group, patients were treated with re-initiation of bari or initiation of the other DMARDs in the event of flare. We investigated the serial changes of patients treated with re-initiation of bari in CDAl after flare.

Results: The baseline characteristics of the patients are summarized in Table. The titer of RF was lower in D group than that in $\mathrm{C}$ group. There were no significant differences in any other items. Ten of $23(43.4 \%)$ in D group remained bari-free without disease activity flare. Serial changes of CDAI were summarized in Figure. CDAI in D group significantly increased from 3.6 at baseline to 9.8 at last observation. LDA rates in $\mathrm{C}$ group were $92.9 \%$ at last observation. CDAI in $\mathrm{C}$ group did not change throughout the follow-up period. CDAl at last observation was higher in $\mathrm{D}$ group than that in $\mathrm{C}$ group. HAQ-DI in D group changed from 0.28 at baseline to 0.45 at last observation. There was no significant change in $\mathrm{HAQ}-\mathrm{DI}$ between both groups $(P=0.28)$. In $D$ group, rescue by re-administration of bari or other DMARDs induced improvement, reducing CDAI from 15.5 at disease flare to 6.8. Especially, all patients treated with re-initiation of bari resulted in re-introduction of LDA in this study.

Table. Characteristics of patients at baricitinib initiation

\begin{tabular}{lccc}
\hline & D group $(\mathrm{n}=23)$ & C group $(\mathrm{n}=28)$ & p-value \\
\hline Age (years) & $66.9(8.6)$ & $67.9(12.7)$ & 0.31 \\
Gender, female, $\mathrm{n}(\%)$ & $6(73.9)$ & $24(85.7)$ & 0.49 \\
Disease duration (years) & $7.6(10.3)$ & $8.3(9.9)$ & 0.37 \\
Prior use of biologics, $\mathrm{n}(0 / 1 / 2 / \geq 3)$ & $(21 / 2 / 0 / 0)$ & $(17 / 6 / 4 / 1)$ & --- \\
MTX (mg/w) & $5.5(3.8)$ & $4.9(4.3)$ & 0.62 \\
PSL $(\mathrm{mg} / \mathrm{d})$ & $1.4(1.9)$ & $0.9(0.9)$ & 0.51 \\
RF, U/ml & $99(141)$ & $187(214)$ & 0.04 \\
ACPA, U/ml & $135(173)$ & $194(214)$ & 0.11 \\
CDAl & $24.4(9.2)$ & $22.5(9.7)$ & 0.36 \\
HAQ-DI & $0.83(0.49)$ & $0.83(0.52)$ & 0.98
\end{tabular}

Figure
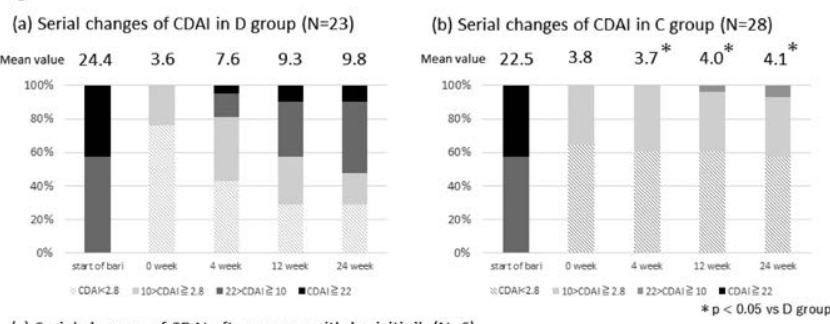

(c) Serial changes of CDAl after rescue with baricitinib $(\mathrm{N}=6)$

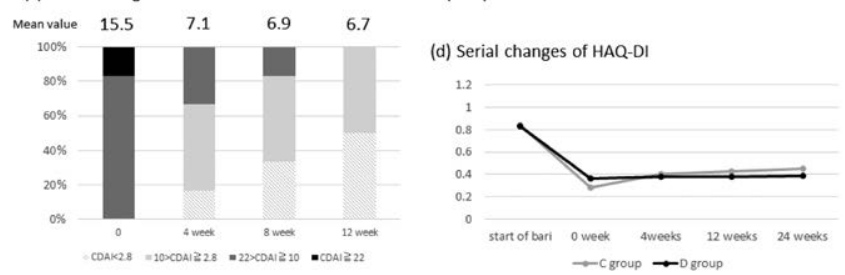

Conclusion: It was possible to discontinue bari without flare in about $43 \%$ of patients with RA. Overall the patients treated with re-initiation of bari could result in re-introduction of LDA without deterioration of HAQ-DI.

\section{References:}

[1] Tanaka $Y$ et al. Mod Rheumatol. 2018;28:583-91

[2] Tanaka Y et al. Mod Rheumatol. 2018;28:20-9

Disclosure of Interests: Eiji Torikai: None declared, Yuji Hirano Speakers bureau: Tanabe-Mitsubishi, Pfizer, Eisai, Abbie, Chugai, Bristol-Meyers, Jansen, Astellas, UCB, Eli-Lilly, Asahikasei, Daiichi-Sankyo, Amgen, Daisuke Suzuki: None declared, Yasuhide Kanayama: None declared DOI: 10.1136/annrheumdis-2020-eular.1546

\section{\begin{tabular}{|l|l|l|l}
\hline FRI0138 & THE IMPACT OF UPADACITINIB VERSUS
\end{tabular} METHOTREXATE OR ADALIMUMAB ON INDIVIDUAL AND COMPOSITE DISEASE MEASURES IN PATIENTS WITH RHEUMATOID ARTHRITIS}

R. Van Vollenhoven ${ }^{1}$, A. Ostor ${ }^{2}$, E. Mysler ${ }^{3}$, N. Damjanov ${ }^{4}$, I. H. Song ${ }^{5}$, Y. Song ${ }^{5}$ J. Suboticki ${ }^{5}$, V. Strand ${ }^{6}{ }^{1}$ Amsterdam Rheumatology and Immunology Center ARC, Amsterdam, Netherlands; ${ }^{2}$ Cabrini Medical Centre, Monash University, Malvern, Australia; ${ }^{3}$ Organización Medica de Investigación, Buenos Aires, Argentina; ${ }^{4}$ Institute of Rheumatology, Belgrade University School of Medicine, Belgrade, Serbia; ${ }^{5}$ AbbVie Inc., North Chicago, United States of America; ${ }^{6}$ Division of Immunology/Rheumatology, Stanford University, Palo Alto, United States of America 